Journal of Social Sciences 5(3): 212-215, 2009

ISSN 1549-3652

(C) 2009 Science Publications

\title{
Cognitive and Non-Cognitive Characteristics as Determinants of Success in Professional Courses at Undergraduate Stage
}

\author{
Zebun Nisa Khan \\ Department of Education, Aligarh Muslim University, Aligarh-202002, India
}

\begin{abstract}
Problem statement: Professional education is the principle means of the developing the human resource. Students who do not perform well in professional courses are not in any way better than those who do not have professional knowledge, because their chances of employment and efficient working are bleak. The present study attempted to examine success in different professional courses at undergraduate level in relation to cognitive and non-cognitive characteristics. Approach: The sample of 450 students (girls and boys) was selected from medical, engineering, law, library science and teacher education of AMU Aligarh India. The population was taken to be reasonably homogenous from the socio economic point of view. It also caters students from the whole country. Suitable Psychological tests were administered on the subjects of the present study to obtain scores on cognitive (intelligence and creativity) and non-cognitive (personality characteristics and socio-economic status) variables. The final achievement scores (at the completion of their respective courses) of the students were considered to be criterion variable. Attempts were made to see that scores obtained satisfy the basic assumption of correlational techniques. Results: The engineering students were at the highest intellectual level while the group of medicine students stands second. The other groups, in descending order were library science and teacher education. Significant relationships between creativity with academic achievement irrespective of professional courses were studied. The personality factors such as-reservedness, impulsiveness, dominance, expediency, harshness and perseverance were found to be the best predictors of success in above professional courses. Socio-economic Status was measured in terms of scores and it was found that socio-economic status had a significant and positive correlation with successful achievement in the professional courses viz engineering, medicine, library science and teacher education. Conclusion: The efficiency of a person depended not only on education and training received by him/her but also on his/her cognitive as well as non-cognitive factors. These factors determined the attitude, interests and the degree of motivation of the students for professional studies.
\end{abstract}

Key words: Cognitive, non-cognitive, reserved, impulsive, dominance, expedient, harsh, perseverance, trusting, suspicious, conscientious, fickle-minded, stable, factor analysis, multiple regression

\section{INTRODUCTION}

Economic growth, social welfare and prosperity of a nation depend on its natural resources and the physical capabilities as well as mental health of its citizens. However, the intellectual talent of the people is more important than natural resources. Natural resources like coal and minerals, precious stones and metals may be the proud possession of a nation, but perhaps more important than this is the human genius that can explore, locate and exploit this treasure and add to the country's material and cultural growth and development. The major instrument that facilitates this development is education. Education is being increasingly recognized as a vehicle for upward social mobility. Professional education is the principal means of developing the human resource. This includes education and training of engineers, teachers, lawyers, doctors, librarians, computer personnel's and administrators. Every nation spends a lot of money on development of professional individuals.

Students who do not perform well in professional courses are not in any way better than those who do not have professional knowledge because their chances of employment and efficient working are bleak. The efficiency of a person in a given profession depends, not only on education and training received by him/her, but also on some of his/her personality characteristics. One cannot make excellent furniture out of bad timber. The factors that influence success in different 
professional courses may include cognitive abilities like-intelligence and creativity; personality traits like confidence, adjustment, level of aspiration, perseverance, conscientiousness and other variables such as socio-economic status of the family. These factors determine the attitudes, interests and the degree of motivation of the students for professional studies.

Prior to the implementation of $10+2$ pattern of school education, diversification of courses in terms of professional and academic started at the age of 13+ when student entered college. The students at this age are not mature enough to take important decisions about their future career. Moreover, their talents and aptitudes are not likely to have crystallized fully at this age to enable them to take judicious decisions in this regard. Due to forces of market economy, professional courses in the institutions of higher learning have acquired significant social recognition and prestige. After passing senior secondary examination, most of the students appear in competitive tests for admission to various professional courses, but due to availability of limited number of seats many of them do not find a place in such courses and consequently, have to join academic courses. Now, the basic question is: "What are the factors associated with success in professional courses?" If an answer to this question were found, it would be possible to guide students to prepare better for competitive admission tests. Through the proposed study, the investigator has attempted to seek answer to this question. This will help to identify factors associated with success in professional courses. It is imperative that only those students should be admitted to specific professional courses at the undergraduate level, which have requisite ability and motivation to complete those courses successfully.

The research studies undertaken so far have been concerned with different aspects of the problem in isolation instead of looking at the problem as a whole. Most of the investigators in this field have studied the impact of different psychological and physiological factors in academic and professional performance of students. There is hardly any study, which has investigated into the role of combined correlates of success in professional courses at the undergraduate level. The study reported here was aimed at achieving this goal.

Objectives: In specific terms the present study was planned to achieve the following objectives:

- To study the prognostic value of components of intelligence and creativity (cognitive variables) for success in professional courses
- To study the prognostic value of personality traits and socio-economic status (non-cognitive) for success in professional courses

- To analyze the inter correlation matrix obtained by correlating predictor variables and the criterion of success (Final achievement scores in professional courses) in order to arrive at smaller number of significant factors explaining the criterion variable

- To investigate the gender differences in variables which potentially predict the performance of students in professional courses

\section{MATERIALS AND METHODS}

A representative sample of 450 students including both boys and girls studying in Medicine, Engineering, Law, Library Science and Teacher Education were selected. Selection of adequate research tools is the most important part of a research. Suitable measures of intelligence, creativity, personality dimensions and socio-economic status were administered to a sample of students studying in aforementioned professional courses. In all, the study involved four predictor variable and one criterion variable.

\section{Predictor measures:}

- Cognitive variables: Intelligence: Indian Adaptation of Psychological Examination of American Council of Education

- Creativity: Test of Creativity constructed on the basis of Torrence Test of Creativity

\section{Non cognitive variables:}

- Personality: Personality Inventory by Rani

- Socio-economic Status: Verma and Saxena's Socio Economic Index

Criterion measure: The Final achievement of the students of Medicine, Engineering, Law, Library Science and Teacher Education at the completion of their respective courses was culled out from the records of the concerned Faculties of Aligarh Muslim University Aligarh India.

Statistical treatment and analysis of data: The study was planned to identify cognitive and non-cognitive variables as determinants of performance in professional courses at the undergraduate level on the basis of extensive study of previous research and theoretical rationale. The variables were measured by 
using suitable psychological tests. The data were analyzed by employing the Factor Analysis techniques.

Coefficients of correlation among different variables including the final achievement scores were computed. The correlation matrix so obtained was factor analyzed by using Principal Axis Method. The extracted factors were rotated using the Varimox Criterion of Simple Structure. A factor loading of 0.30 and above was considered significant for a particular factor. The facility of computer was employed to compute coefficient of correlation and factor loading. The inter correlation matrix so obtained was factor analyzed in order to arrive at smaller number of variable suitable for predicting success of students in different professional courses. The factors obtained were interpreted in the light of connation of variable getting high loading on different factors and can be used to predict future performance in all selected professional courses with the help of selected predictor variables. These results would go a long way in guiding students preparing for competitive tests and in making career choice and could help to predict the performance of an individual student in future.

\section{RESULTS}

The present study has come out with the following main findings with reference to relationship between Intelligence and Academic achievement of aforementioned professional courses at the undergraduate level:

- The students of Engineering and Medical possessed a higher level of Verbal intelligence than those of Teacher Education, Law and Library Science

- The students of Engineering, Medical, Teacher Education. Law and Library Science possessed a higher level of Non-verbal intelligence

- Creativity is very important aspect of the intellect. A significant relationship was found between creativity (originality, flexibility and fluency) with academic achievement irrespective of Professional courses studied

The following personality factors were found to be the best predictors of success in professional courses noted against each:

- Reservedness: Engineering, Teaching, Law and Medical

- Impulsiveness: Engineering, Teaching Education, Law and Library Science
Table 1:Comparison by gender

\begin{tabular}{ll}
\hline High achieving boys & High achieving girls \\
\hline Impulsive & Stable \\
Suspicious & Trusting \\
Expedient & Persevering \\
Fickle minded & Conscientious \\
Belongs to low & Belongs to high \\
Socio-economic status & Socio-economic status \\
\hline
\end{tabular}

- Dominance: Engineering, Teaching Education, Law and Library Science

- Expediency: Engineering, Law, Library Science and Medical

- Harshness: Engineering, Teaching Education, Law and Library Science

- Perseverance: Engineering, Teaching Education, Law and Medical

It was found that socio-economic status had a significant and positive correlation with successful achievement in the aforementioned professional courses viz; Engineering, Medical, Library Science, Teacher Education and Law.

The present study has come out with the following sex difference regarding high achieving girls and boys (Table 1).

\section{DISCUSSION}

Success in professional courses is dependent upon intelligence as well as other personal factors. Intelligence determines what the person can do and the other factors determine what the person will do. Mathur $^{[12]}$ attempted to investigate into the level of intelligence of students selected for admission to four professional courses-Engineering, Medicine, Law and Teachers Training. He administered American Council of Education Test of Intelligence to students selected for admission to the above mentioned courses and found an overall difference of approximately 10 points from Engineering to Teaching in that order. The differences between all the groups, except that between Law and Training, were statistically significant. $\mathrm{Khan}^{[3,5,9]}$, also concluded that intelligence is significantly and positively related to success in the academic as well as professional courses.

It is generally believed that creative children are too much involve in their creative Endeavour and generally do not excel in academic/professional courses. This myth has however been belied by the pioneering study of Getzel and Jackson ${ }^{[4]}$ who found that the lack of conformity with the popular view is perhaps the cause of the fact that to be creative one must have high level of intelligence. Passi ${ }^{[7,9,10,12]}$, 
obtained a significant relationship between creativity and performance in academic/professional courses. However, Getzel ${ }^{[4]}$ has not observed any such relationship. This was due to the reasons such as inadequate size of the sample, defective design of the studies and shortcomings in the measuring tools.

Human personality is a very complex phenomenon. The word personality has been derived from a Latin word persona, which means a mask. In fact, personality is the combination of effects made by an individual upon himself / herself and by others including his / her professional efficiency. Arora ${ }^{[1,5,7,10]}$, have reported that personality characteristics play a significant role in predicting professional success. Professional efficiency is a function of intellectual and personal characteristics of the individual and the influence of his / her home. Research conducted to predict professional efficiency has come out with finding and confirming highly significant role of personality. Some of them are studied by Elva ${ }^{[2,11]}$.

The socio economic status of a family is an important variable for the selection of professional course of its ward. Researches conducted to predict the success in different professions are likely to come out with highly significant indices. Mathur ${ }^{[8]}$ and $\mathrm{Khan}^{[6]}$ are of the opinion that socio-economic status had a significant and positive relationship with the selection of different stream of courses.

\section{CONCLUSION}

On the basis of above findings the conclusion could be drawn that cognitive as well as non cognitive variables plays an important role for predicting success in these professional course viz Medical, Engineering, Library Science, Teacher Education and Law. It is imperative that only those students should be admitted in the above mentioned courses at the undergraduate level that had requisite ability and temperament which are likely to succeed in them. The choice of the professional courses is made according to the above mentioned cognitive and non-cognitive factors associated with success in professional courses.

\section{REFERENCES}

1. Arora, R.K., 1981. An investigation into the problems of students in professional courses of medicines, law, engineering and education in relation to personality factors. Ph.D. (Edu.) AMU., Aligarh.

www.education.nic.in/cd50years/g/z/9I/0Z9I0101. htm
2. Elva, B., 1953. Personality factors of over and under achievers in engineering. Educ. Psychol., 16:536-543.

http://psycnet.apa.org/index.cfm?fa=main.doiLandi ng\&uid=1957-08811-001

3. Chauhan, C.P.S., 1982-3. An evaluation of achievement in algebra of class IX students in Delhi schools with reference to categories of Guilford's structure of Intellect Model, Ph.D. Edu. JMI.

www.education.nic.in/cd50years/g/z/9j/0Z9J0E09. htm

4. Getzel, J.W. and P.W. Jackson, 1962. Creativity and Intelligence, Explorations with Gifted Children. Willey, New York. www.crearmundos.net/.../entre\%20a\%20teoria $\% 20$ e\%20a\%20pratica.htm

5. Khan, Z.N., 2000. Personality profile in the postgraduate professional courses. Educ. Rev., 106: 74-76. www.scipub.org/fulltext/jss/jss128487.pdf

6. Khan, Z.N., 2001. A factorial study among certain basic skills in arithmetic and pupils achievement. J. Educ. $\quad$ Psychol., 59: 1-9. www.scipub.org/fulltext/jss/jss1284-87.pdf

7. Kumar, G., 1978. Creative functioning in relation to personality value orientation and achievement motivation.Ind.Educ.Rev.,13.

www.linkinghub.elsevier.com/retrieve/pii/S019188 6996001626

8. Mathur, M.B., 1966. A comparative study of levels of intelligence among professional groups. Ph.D. (Psy.) AMU. Aligarh. www.education.nic.in/cd50years/g/Z/9J/0Z9J0E01.htm -

9. Negi, S., 1993. Creativity, intelligence and academic achievement. Dissertation M.Ed. (Edu.), AMU., Aligarh. www.scribd.com/doc/2566413/References

10. Passi, B.K., 1972. An exploratory study of creativity and its relationship with intelligence and achievement in school subjects at high secondary stage. Ph.D. (Edu.) Punjab University. dspace.vidyanidhi.org.in:8080/...JMI-2000-257Bibliography.pdf

11. Rani, S., 1994. Personality profiles of over and under achievers in professional courses. Ph.D. (Edu.) AMU., Aligarh. www.findarticles.com/p/articles/mi_7076/is_2_1/ai/pg_5

12. Toongs, S., 1982. Vocational aspiration in relation to creativity, personality, achievement and socioeconomic status of high school students. Ph.D. (Edu.), Pan University. www.education.nic.in/cd50years/g/z/9j/0Z9J0E19.htm 